\title{
CONSTITUCIÓN BRASILEÑA DE 1988: AVANCES Y RETROCESOS EN LA PROTECCIÓN DEL DERECHO FUNDAMENTAL DEL TRABAJO
}

\author{
CONSTITUIÇÃO BRASILEIRA DE 1988: AVANÇOS E \\ RETROCESSOS NA PROTEÇÃO DO DIREITO FUNDAMENTAL DO \\ TRABALHO
}

BRAZILIAN CONSTITUTION OF 1988: ADVANCES AND RETROCESSES IN THE PROTECTION OF FUNDAMENTAL LABOR LAW

MARCO ANTÔNIO VILATORRE

Pós-Doutor pela Universitá degli Studi di Roma II, "Tor Vergata" (2014). Doutor em Diritto del Lavoro, Sindacale e della Previdenza Sociale - Università degli Studi di Roma, "La Sapienza" (2001), revalidado pela Universidade Federal de Santa Catarina. Mestre em Direito pela Pontifícia Universidade Católica de São Paulo (1998). Presidente do Instituto brasileiro de Ciências Jurídicas e Sociais (IBCJS). ExPresidente da Associação dos Advogados Trabalhistas do Paraná (2009-2011). Professor do UNINTER. Professor Adjunto III da Graduação e do Programa de PósGraduação em Direito (Mestrado e Doutorado) da Universidade Federal de Santa Catarina. Membro do Centro de Letras do Paraná. Acadêmico da cadeira número 73 da Academia brasileira de Direito do Trabalho. Selecionado pela Secretaria do MERCOSUL em 15 de dezembro de 2005 como Consultor do MERCOSUL para elaborar legislação sobre a Livre Circulação de Mão de Obra no MERCOSUL (2005/2006). Tem experiência na área de Direito, atuando principalmente nos seguintes temas: Direito do Trabalho, Processo do Trabalho e Direito Internacional. 


\section{MIRIAM OLIVIA KNOPIC FERRAZ}

Doutoranda em Direito pela PUCPR (bolsista PROSUP). Mestre pela PUCPR. Especialista em Direito Constitucional pela ABDCONST. Pós-graduanda Legal Tech: Direito, Inovação e Start Ups pela PUC Minas. Editora Adjunta da Revista da ABDCONST. Membro Núcleo de Estudos de Pesquisas em Tributação, Complexidade e Desenvolvimento e do Grupo de pesquisa Análise Econômica do Direito da PUCPR. Membro da Comissão de Igualdade Racial e da Verdade da Escravidão Negra da OABPR. Desenvolve pesquisa na área de Direito Constitucional e Direito ao/do Trabalho.

\section{LINCOLN ZUB DUTRA}

Doutorando em Direito pela Pontifícia Universidade Católica de Paraná - PUCPR (previsão de conclusão em 2021). Mestre em Direitos Fundamentais e Democracia pelo Centro Universitário Autônomo do Brasil - UNIBRASIL (2017). Pós-Graduado em Direito do Trabalho e Processo do Trabalho pela Pontifícia Universidade Católica do Paraná (2013). Graduado em Direito pela Pontifícia Universidade Católica do Paraná (2012). Advogado inscrito na OAB/PR sob número 65.048. Experiência em Direito Empresarial, Trabalhista, Cível e Societário. Experiência no meio Corporativo Empresarial. Com vivência no exterior, Miami/EUA (2000) e Vancouver/CA (2009). Professor Universitário (Universidade Católica de Santa Catarina). Professor no programa de Pós-Graduação da Universidade Católica de Santa Catarina (Joinville, Jaraguá do Sul e São Bento do Sul). Professor no programa de Pós-Graduação da UNIVILLE. Professor no programa de Pós-Graduação da Pontifícia Universidade Católica de Paraná - PUCPR. Professor no programa de Pós-Graduação da Faculdade Estácio. Professor no Ordem Mais Ordem Mais Curso Preparatório para Concursos Públicos.

\section{RESUMEN}

Objetivo: El estudio pretende una reflexión acerca de los avances y retrocesos en la protección del derecho fundamental al trabajo; una demostración de la interacción 
entre teoría y práctica para atender a la necesidad de transformación social; y una implantación y protección de los derechos fundamentales en las relaciones sociales, del trabajo y de las empresas.

Metodología: A través del método hipotético deductivo de la revisión bibliográfica, con utilización del derecho comparado y del análisis económico constitucional del derecho del trabajo se buscará reflexionar acerca de los avances y retrocesos en la protección del derecho fundamental al trabajo.

Resultados: El hallazgo obtenido de la investigación permite concluir que, aunque treinta años después de la Constitución brasileña de 1988, su efectividad aún encuentra varias barreras, lo que la convierte en una carta de intensiones. Como resultado, también es posible ver una frustración latente frente a varias regulaciones infra-constitucionales que corrompen, deconstruyen la predicción constitucional, distorsionan el ideal democrático y forman una sociedad justa e igualitaria. Sin embargo, como resultado, la investigación es esperanzadora con el texto constitucional, ya que existe un control de constitucionalidad y convencionalidad para garantizar la efectividad del texto de la Carta Magna, en particular la legislación laboral.

Contribuciones: La contribución del estudio radica en la lectura constitucional de las relaciones sociales, especialmente en la protección de los derechos sociales, en particular, el derecho laboral. Por lo tanto, incluso si las leyes infra-constitucionales difieren del texto constitucional, existen medidas (control de constitucionalidad y convencionalidad) como mecanismos capaces de resistir a los ataques contra el ideal constitucional de una sociedad igualitaria, justa y solidaria.

PALABRAS-CLAVE: Constitución; constitución del trabajo; fuerza normativa; derechos fundamentales sociales; derecho fundamental al trabajo.

\section{ABSTRACT}

Objective: To reflect on the advances and setbacks in the protection of the fundamental right to labor; demonstrate the interaction between theory and practice to meet the need for social transformation; and implementation and protection of fundamental rights in social, labor and business relations.

Methodology: By way of the hypothetical deductive method of bibliographic review, with the use of comparative law and constitutional economic analysis of labor law, it will seek to reflect on the advances and setbacks in the protection of the fundamental right to labor.

Results: The finding obtained from the investigation allows to conclude that, although thirty years after the Brazilian Constitution of 1988, its effectiveness still 
meets several barriers, which turns it into a letter of intentions. As a result, it is also possible to see a latent frustration in view of various infra-constitutional regulations that corrupt, deconstruct constitutional prediction, distort the democratic ideal and form a just and egalitarian society. However, as a result, the investigation is hopeful with the constitutional text, since there is a constitutionality and conventionality control to guarantee the effectiveness of the Magna Carta text, in particular labor legislation.

Contributions: The contribution of the study lies in the constitutional reading of social relations, especially in the protection of social rights, in particular, labor law. Therefore, even if the infra-constitutional laws differ from the constitutional text, there are measures (control of constitutionality and conventionality) as mechanisms capable of resisting attacks against the constitutional ideal of an egalitarian, just and supportive society.

KEYWORDS: Constitution; labor constitution; normative force; fundamental social rights; fundamental right to labor.

\section{RESUMO}

Objetivo: O estudo visa uma reflexão sobre os avanços e retrocessos na proteção do direito fundamental ao trabalho; uma demonstração da interação entre teoria e prática para atender à necessidade de transformação social; e uma implementação e proteção dos direitos fundamentais nas relações sociais, trabalhistas e comerciais.

Metodologia: Por intermédio do método hipotético dedutivo de revisão bibliográfica, com o uso do direito comparado e da análise econômica constitucional do direito do trabalho, busca-se refletir sobre os avanços e retrocessos na proteção do direito fundamental ao trabalho.

Resultados: O resultado obtido com a investigação permite concluir que, apesar de trinta anos após a promulgação da Constituição Brasileira de 1988, sua eficácia ainda encontra várias barreiras, o que a torna uma carta de intenções. Como resultado, também é possível ver uma frustração latente diante de vários regulamentos infraconstitucionais que corrompem, desconstroem a previsão constitucional, distorcem o ideal democrático e formam uma sociedade justa e igualitária. No entanto, como resultado, a investigação é esperançosa com o texto constitucional, uma vez que existe um controle de constitucionalidade e convencionalidade para garantir a efetividade do texto da Magna Carta, em particular a legislação trabalhista.

Contribuições: A contribuição do estudo está na leitura constitucional das relações sociais, especialmente na proteção dos direitos sociais, em particular o direito do trabalho. Portanto, mesmo que as leis infraconstitucionais diferenciem-se do texto 
constitucional, existem medidas (controle da constitucionalidade e da convencionalidade) como mecanismos capazes de resistir a ataques contra o ideal constitucional de uma sociedade igualitária, justa e solidária.

PALAVRAS-CHAVE: Constituição; lei trabalhista; força normativa; direitos sociais fundamentais; direito fundamental ao trabalho.

\section{INTRODUCCIÓN}

La Constitución brasileña de 1988 representó una ruptura de paradigmas y la consolidación de la importancia y necesidad de protección de los derechos fundamentales y de los derechos fundamentales sociales. En especial al derecho al trabajo se dedicó en diversos dispositivos y profundizó las protecciones de esos derechos, tanto en el ámbito del individuo como en la constitucionalización de bases del sistema sindical.

A este estudio resta estudiar cómo la Constitución de 1988 estructuró tales derechos, formando la multidimensionalidad y la multiplicidad de los derechos fundamentales al trabajo. Además, la construcción de un ordenamiento jurídico fuerte en cuanto a derechos fundamentales pasó por la ampliación significativa de tales derechos, por medio de la disposición del propio art. $5 \S 2^{\circ}$, al ampliar y posibilitar la adaptación de un rol de derechos fundamentales ligado a la realidad ya las expectativas sociales e internacionales.

En un segundo momento se apunta la efectiva protección de los derechos fundamentales en Brasil, demostrando los institutos presentes e innovados en la Constitución que han fortalecido e instituido un régimen jurídico especial, calcado en la aplicabilidad inmediata y en la protección a alteraciones supresiones por medio de las cláusulas pétreas. En este estudio se demuestra que dicho régimen abarca y comprende los derechos fundamentales sociales, en particular el derecho al trabajo. Además, la protección se extiende por el bloque de constitucionalidad y por el bloque de laboratividad, que se demuestra, ambas teorías, fortalecidas en el ordenamiento. 
Por último, se analiza cómo las reformas legislativas en carácter constitucional e infraconstitucional deben ser pensadas y repensadas dentro de un ordenamiento jurídico con una Constitución formalmente fuerte, estructurada y protectiva. Se profundiza la necesidad del paso por el filtro de la constitucionalidad y convencionalidad de forma previa, y ante la realidad, la necesidad de la realización de esa salvaguardia de forma posterior, incluso abarcando el instituto de la prohibición del retroceso y de la progresividad de los derechos fundamentales.

El presente artículo, a través del método hipotético deductivo, de la revisión bibliográfica, del derecho comparado y del análisis económico constitucional del derecho del trabajo, buscará reflexionar acerca de los avances y retrocesos en la protección del derecho fundamental al trabajo, en especial después de la promulgación de la Constitución brasileña de 1988.

En el marco de la exposición, la relación con la misión y el enfoque de la Revista Jurídica editada por el Programa de Maestría en Derecho Empresarial y Ciudadanía (UNICURITIBA) se da directamente, pues indica reflexionar sobre la preocupación con los principios éticos y con el respeto a la dignidad humana. Abordar de manera crítico-reflexiva la realidad y el conocimiento. Demostrar la interacción entre teoría y práctica para atender a la necesidad de transformación social. Implantación y protección de los derechos fundamentales en las relaciones sociales, del trabajo y de las empresas. Efectividad y Colisión de derechos fundamentales en las relaciones sociales, empresariales y del trabajo. Los nuevos derechos fundamentales sociales, del trabajo y empresariales se complementan con el papel del negocio jurídico en la actualidad: una visión de futuro - la protección del empleo, la salud y la vida privada de los trabajadores. Psicodinámica del trabajo. Psicología jurídica. Derechos humanos del trabajador. Derecho internacional de los derechos humanos del trabajador y el derecho brasileño. El sistema internacional de protección de los derechos humanos del trabajador. Normas internacionales de protección de los derechos humanos del trabajador. Constitucionalismo Social. Constitucionalización del Derecho del Trabajo. 


\section{LA COMPOSICIÓN DE LA CONSTITUCIÓN DEL TRABAJO EN BRASIL}

La Constitución de 1988 es un marco para la protección del derecho fundamental del trabajo, incluso se apunta como el camino para el compromiso de la democratización de la gestión laboral. (DELGADO; 2015, p. 128)

Se observa que la Constitución de 1988 ya en pie de Preámbulo estipula que la valorización de los derechos sociales e individuales y hace mención la búsqueda por una sociedad pluralista. En los propios principios fundamentales se estipuló la dignidad humana, el valor social del trabajo, la libre iniciativa, el objetivo de una sociedad libre, justa e igualitaria. (ALMEIDA; ALMEIDA, p. 116)

Los derechos inherentes al trabajo se colocaron en la constitución en el Título I (posicionándose en los principios fundamentales), pero efectivamente en el Título II en los Derechos y garantías fundamentales, como derechos sociales y elevó el trabajo, los derechos inherentes al trabajo y el derecho del trabajo a la sociedad condición de elementos constitutivos del orden constitucional (ALMEIDA; ALMEIDA, p. 116), y así protegidos y tutelados por el ordenamiento de forma efectiva y prioritaria.

Principalmente, el punto crucial es que la Constitución de 1988 ha innovado (en comparación con las Cartas Magnas anteriores) en el sentido de emanar todo el poder del pueblo, por medio de sus representantes electos o directamente. (DELGADO; 2015, p. 128) Tal deseo es vislumbrado no sólo en la posibilidad de plebiscito y referéndum (BENEVIDES; 1991, p.40), (art. 14, CRFB/1988), como también por la valorización de las convenciones y acuerdos colectivos (art. 7으, XVI e 8으, VI da CRFB/1988).

En el capítulo II del Título II, que comprenden los artículos 6 al 11, la Constitución consolidó su interés en proteger y elegir el nivel constitucional a los derechos del trabajo, al realizar la constitucionalización del derecho del trabajo la CRFB / 1988 impuso al resto del universo jurídico una influencia e inspiración justobalistas hasta entonces desconocidas en la historia del país. (DELGADO; 2015, p. 130) El Código de Defensa del consumidor (Ley no 8.078 / 1990) es una de las 
más importantes representaciones de esa influencia juslaboralista, pues incluye, incorpora institutos clásicos del derecho del trabajo. ${ }^{1}$

La influencia de la Constitución de 1988 en la lógica jurisdiccional fue crucial para el establecimiento de nuevas bases para el derecho del trabajo como la igualdad de derechos para los trabajadores urbanos y rurales (artículo 7, "caput") y extendiendo a los trabajadores sueltos (art. 7ํ, XXXIV); avanzó de forma significativa en los derechos de las trabajadoras domésticas (artículo 7, párrafo único); se amplió las protecciones jurídicas a la empleada gestante por medio de la licencia previsional de 120 días (artículo 7, XVIII), sea por la estabilidad (Art. 10, II, b), ADCT); amplió la licencia paternidad para cinco días (artículo 7, XIX y art. 10, § $1^{\circ} \mathrm{ADCT}$ ); suprimió el aviso previo de 8 días y amplió para treinta días (artículo 7, XXI); extendió la prescripción para cinco años (artículo 7, XXIX, "a") entre otros.

En el marco de la Convención de las Naciones Unidas sobre el Derecho de los Estados Unidos de América, (artículo 8) y la huelga (artículo 9); la constitución reconoció la "subjetividad política de la clase obrera" (HERRERA, 2015, p.53), por medio de "derechos de participación, asociación, reunión, huelga y negociación colectiva" (ALMEIDA; ALMEIEDA, 2017, p.117), permitiendo así el alcance de la transformación social por medio de la "lucha democrática, electoral y sindical". (HERRERA, 2015, p. 53)

La revolución y la nueva postura que la Constitución de 1988 adoptó pueden ser explicadas, según Márcio Túlio Viana, por tres fenómenos de los años 80: 1. el fortalecimiento del sindicato, resultado del aumento de los parques industriales, pero también del fuerte movimiento de bases; 2 . el fin de la dictadura que trajo la idea de valorización de los derechos humanos; 3 . el hecho de que el movimiento sindical percibe la existencia de una tendencia a la "flexibilización" en los países centrales, y así el objetivo / necesidad de proteger las propias normas de protección contra cambios futuros. (VIANA, 2007, p. 181-183). De esta forma, los dispositivos e

\footnotetext{
${ }^{1}$ La propia noción de ser colectivo fue incorporada a partir de la lógica de colectividad de personas, aunque indeterminadas; la responsabilización objetiva que es noción clásica del Derecho del Trabajo; el principio de la norma más favorable entre otros. (DELGADO, 2015, p.130)
} 
intenciones se desdoblan y forman la Constitución del Trabajo en Brasil ${ }^{2}$, es el análisis detallado, ya que representa el bloque de protección de los derechos relacionados con el trabajo.

En un primer momento, la constitución reconoce el derecho al trabajo en el art. 6, y también, segundo, Gustavo Zagrebelsky (2013, p.39)

de forma implícita en el principio del valor social del trabajo. Además, la constitución prioriza el trabajo en modalidad de empleo (ALMEIDA; ALMEIDA, 2017, p.117), cuando adopta la búsqueda por el pleno empleo como principio del orden económico ${ }^{3}$ (art.170, VIII), ya que la relación de empleo (basada en el artículo 7 al 11 de la CRFB / 1988) sería la base para el acceso a diversos derechos fundamentales, y de la propia formación del individuo como agente activo. (SEN, 2000, p.334)

Se resalta entonces la multidimensionalidad del derecho al trabajo que plantea varios aspectos de contenido y de eficacia.

La multidimensionalidad está vinculada a la dimensión individual (acceso al

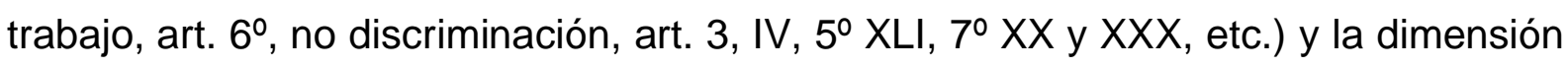
colectiva que "se manifiesta en el derecho a la adopción de políticas públicas orientadas a la aplicación del pleno empleo". (ALMEIDA; ALMEIDA, 2017, p.118) Por otro lado, Leonardo Vieira Wandelli (2013), Ingo W. Sarlet y Mariana Figueiredo (2008, p.14) afirman que el derecho al trabajo (así como los sociales y civiles) incluyen derechos a prestaciones, que implican medidas de realización, derechos de abstención y también medidas de protección.

De forma simplificada, Stefano Giubboni reconoce la existencia de la multiplicidad significativa del derecho al trabajo, subdividiendo en tres órdenes: 1. Derecho social la prestación pública; 2. Derecho de libertad negativa; 3. Derecho de libertad positiva. (GIUBONNI, 2006) Así, el derecho al trabajo puede ser defendido y valorado en las más diversas dimensiones, con los diversos tipos de actuación del Estado y de los entes privados, sea por la apertura de condiciones para la

2 Terminología adoptada por Cleber Lúcio de Almeida y Wania Guimarães Rabêllo de Almeida en: ALMEIDA; ALMEIDA, 2017, p. 117.

3 También es consecuencia del Protocolo adicional a la Convención Americana sobre Derechos Humanos. 
realización del pleno empleo, sea por la abstención y consecuente libertad para el acceso al trabajo y también por la protección contra conductas abusivas y discriminatorias.

Además, además de ser un derecho fundamental, el derecho al trabajo es un derecho humano protegido por diversas cartas internacionales que Brasil es signatario, como por ejemplo la Declaración Universal de los Derechos Humanos (artículo XXIII, I), el Protocolo Adicional a la Convención De los derechos humanos en materia de derechos económicos, sociales y culturales (Protocolo de San Salvador) (artículo 6) y etc.

De forma paralela, también son componentes de la Constitución del Trabajo:

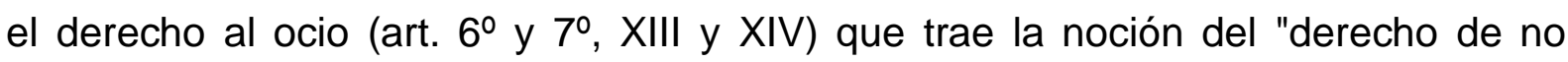
trabajar" (REALE; 1980, p.115-120) y el "derecho a la desconexión" (DUTRA; VILLATORE, 2014, p. 142-149); a la protección de la maternidad y de la infancia (artículo 6); la asistencia en caso de pérdida o reducción de la capacidad de trabajo o desempleo voluntario (artículos 6 y 7, II); mejora de la condición social (art. $7^{\circ}$ caput); a la protección contra dispensa arbitraria o sin justa causa (artículo 7, I y artículo 10 del ADCT); el FGTS (artículo 7, III); el salario mínimo que sea capaz de atender las necesidades vitales del propio individuo como de sus familiares y nunca inferior al mínimo, además de proporcional a la extensión de la complejidad del trabajo (Art. 7으, IV, VII y V respectivamente); la irreductibilidad salarial (artículo 7 VI) y así sucesivamente.

Además, es de suma importancia resaltar que en consecuencia del art. $5^{\circ} \S$ $2^{\circ}$, los derechos y garantías expresados en la Constitución no excluyen otros que se deriven de principios constitucionales expresos o implícitos y también del bloque de constitucionalidad. Así, los derechos y garantías fundamentales no son solamente los expresados en la constitución, sino también aquellos que puedan hermenéuticamente transcurrir del régimen democrático adoptado y de los principios constitucionales previstos, además de los que se encuentren en documentos internacionales. (LOPES, 2009, p.47). La Constitución de 1988 en materia de protección de los derechos fundamentales, y aquí, analizada sobre el prisma de la Constitución del Trabajo, adoptó una posición de valorización y reconocimiento de la 
importancia de tales derechos y en nivel de normativa, es revolucionaria y paradigmática.

\section{LA EFECTIVA PROTECCIÓN DE LOS DERECHOS FUNDAMENTALES SOCIALES DE LOS TRABAJADORES}

El primer paso para la efectiva protección de los derechos fundamentales en general, y aquí en especial el del trabajo, está en el reconocimiento de su régimen jurídico especial. Se parte del supuesto de que tales derechos constituyen los supuestos del consenso sobre el cual se debe edificar cualquier sociedad democrática. (PÉREZ LUÑO; 1995, p. 21) Dada la relevancia que tales derechos poseen, es necesario asignarles tal régimen. (HACHEM; 2013, p. 67)

Conforme a la suciedad Robert Alexy, los derechos fundamentales se traducen en posiciones jurídicas que tienen mucha importancia y su reconocimiento no puede quedar a disposición del legislador ordinario (en una mayoría parlamentaria simple). (ALEXY; 2007. p. 395) Por este motivo se inserta la llamada jusfundamentalidad, característica jurídica de que disponen determinados derechos insertados en la Constitución (HACHEM; 2013, p. 67), es decir, característica inherente a los derechos fundamentales.

Carl Schmitt (1973, p. 190) cita que los derechos fundamentales son, "sólo aquellos derechos que constituyen el fundamento del propio Estado y que, por ello y como tal, son reconocidos por la Constitución".

Se aclara que todos los derechos presentan dos dimensiones, una subjetiva y otra objetiva, según aclara Simone Reissinger (2007, p. 1.766): "la dimensión subjetiva de los derechos fundamentales autoriza al titular a reclamar en juicio determinada acción, que puede ser defensiva o prestacional "; en relación a la "dimensión objetiva, significa que los derechos fundamentales, además de conceder una posición subjetiva (individual o colectiva), expresan los valores de determinada sociedad, es decir, comprenden el deber de respeto (incluso de los poderes constituidos) con los derechos fundamental". 
Se destacan dos características que diferencian y marcan el régimen jurídico de los derechos fundamentales, no es posible extender a todos los derechos previstos en la constitución: la aplicabilidad inmediata (artículo $5^{\circ}$, $\S^{1} 1^{\circ}$, CRFB / 1988)

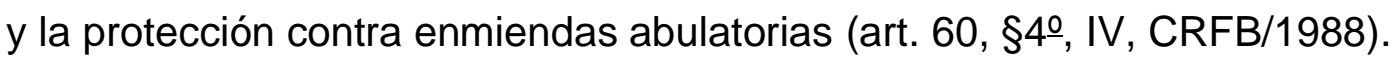

La aplicabilidad inmediata se adoptó como una innovación de la Constitución de 1988, ya pesar de traer mucha discusión, hay un consenso de que tal dispositivo "consagra derechos y garantías fundamentales vinculan directamente a los Poderes Públicos (Ejecutivo, Legislativo y Judicial)" (HACHEM, 2013, 68) y también, produce efectos inmediatos e independientes de reglamentación infraconstitucional. El objetivo principal de esta previsión es servir como mecanismo de superación de la idea de que los derechos fundamentales sólo pueden materializarse tras la formulación de legislación ordinaria.

La protección contra enmiendas abulantes hace que los derechos fundamentales integren las cláusulas pétreas, o sea, están vinculados a límites materiales a la reforma de la Constitución. De nuevo, hay divergencias en la doctrina sobre la incidencia de ese instituto, una de ellas es por el hecho de que el constituyente utilizó la expresión "derechos y garantías individuales", y no fundamentales, y por eso, excluiría los derechos sociales de esa protección. Sin embargo, en este trabajo abogaba por la protección del régimen jurídico de derechos fundamentales entendidos de forma global, y evidentemente abarcando los derechos sociales, y así el derecho al trabajo.

Además, como aclara Jürgen Habermas (2010, p.115), el proceso legislativo democrático necesita confrontar a sus participantes con las expectativas normativas de las orientaciones del bien de la comunidad es necesario extraer en su fuerza limitadora un entendimiento sobre reglas generales de convivencia (HABERMAS, 2010, p.115)

En el caso de los derechos fundamentales se presentan como mecanismos limitadores: crean tensiones entre directas con la democracia, y así, producen un conflicto entre el principio constitucional y el principio democrático, una vez que, que los derechos fundamentales crean límites negativos y positivos al proceso democrático. (BARBOZA; 2007, P.150-151) 
Hay todavía la discusión bajo el aspecto de la legitimidad del Poder Judicial en áreas reservadas al administrador y al legislador, bajo pena de quiebra del principio democrático (REISSINGER, 2007, p.1.767), como lo aclara Clémerson Merlin Clève (2006, p.35), los integrantes del Poder Judicial no fueron elegidos, estando por eso desnudos de legitimidad que sólo podría ser conferida por el sufragio popular. El Poder Judicial, en este caso, estará actuando con el objetivo de proteger a la mayoría permanente (Constituyente) contra la actuación desconforme de la mayoría eventual, coyuntural y temporal (legislatura). (CLÈVE, 2006, p.35)

En la visión de Simone Reissinger (2007, p.1.767), es necesario encontrar un punto de equilibrio para que el juez, comprometido con la efectividad de los derechos fundamentales sociales, no sobrepase ciertos límites que puedan poner en riesgo los postulados del Estado Democrático de Derecho, pero que eso tampoco sea obstáculo a la actuación judicial.

Así, el sistema constitucional brasileño trae un régimen jurídico de protección a los derechos fundamentales, protegiendo de dos formas, según Daniel Wunder Hachem (2013, p.69): 1. En el sentido negativo, al prohibir la ejecución de acciones por el Poder Constituyente Reformador, en enmiendas constitucionales tendentes a abolir tales derechos (art. 60, § 4ํ, IV, CRFB / 1988); 2. En un sentido positivo, al prevenir contra omisiones tanto del legislador, como del administrador y del juez, al estipular la aplicabilidad inmediata (art. 5丷, $\S 1 \underline{\underline{0}}$, CRFB/1988).

La propia idea de que los derechos fundamentales sociales no estarían abarcados por ese régimen jurídico especial, viene de la idea de que los derechos sociales estar restringidos a una realización de legislación ordinaria. La máxima es que los derechos de libertad se realizan por medio de abstención, y los sociales por medio de acción estatal. Sin embargo, lo que se observa, y que se defiende en este estudio, es que todos los derechos fundamentales, tanto de libertad y sociales, poseen variadas funciones: de defensa, de protección y de prestación; y las diferencias de régimen jurídico existen entre cada una de ellas, y no entre esas dos especies de derechos fundamentales, globalmente consideradas. (HACHEM, 2013, p.85) 
Los derechos fundamentales como un todo, en la visión de José Martínez de Pisón (1997, p.17), son los derechos reflejados de forma correspondiente en las Constituciones y por eso, poseen una tutela reforzada. La efectiva protección de los derechos fundamentales sociales de los trabajadores pasará por la comprensión de la multidimensionalidad y de la multiplicidad de esos derechos antes citada, ya que el derecho al trabajo y los derechos laborales necesitan acciones en las tres dimensiones: abstención de la realización de obstáculos; actuación para la promoción de políticas de pleno empleo y valorización de las políticas y normativas protectivas; y actuación en favor del agotamiento de discriminaciones y abusos.

Con esta disposición afirma el ideal constitucional de concretarse no sólo la letra de la constitución, sino también los principios en ella previstos y también los de fuera de ella. (LOPES; MARQUES; 2007, p.42) Es decir, tienen carácter de derecho fundamental todos los pactos y convenciones ratificadas por Brasil que traten de derechos humanos, y así, están sometidos al régimen jurídico de protección de los derechos fundamentales, en especial la protección de las cláusulas pétreas. Así, la efectiva protección de los derechos fundamentales del trabajo está vinculada a la observancia de su consonancia con los tratados y pactos internacionales, que como aseverado anteriormente forman y consolidan nuevos derechos y protección.

Pertenencia a este marco de protección de los derechos fundamentales es el principio de la prohibición del retroceso, que, a pesar de no estar dispuesto expresamente en la Constitución, puede ser entendido como un principio implícito, (NETTO E PINTO; 2010, p.113) y como consecuencia de los principios del Estado Democrático y Social de Derecho; de la dignidad de la persona humana y de la máxima eficacia y efectividad de las normas que definen los derechos fundamentales. (SARLET; 2004, p. 449)

Por otra parte, es entendido por parte de la doctrina como proyección del artículo 60, $\S 4^{\circ}$ de la Constitución, (MURADAS; 2011, p. 40) y el Supremo Tribunal Federal ya se posicionó sobre la existencia de ese obstáculo constitucional a la frustración y al incumplimiento de derechos fundamentales sociales. ${ }^{4}$

${ }^{4}$ [...] A PROIBIÇÃO DO RETROCESSO SOCIAL COMO OBSTÁCULO CONSTITUCIONAL À 
La principal función de este principio es la búsqueda por la protección de la máxima efectividad de las leyes que regulan los derechos sociales de las posibles alteraciones del "legislador futuro", lo que trae una protección para las conquistas realizadas (muy parecido al propio objetivo de las cláusulas pétreas). (SCHIER; 2009, p.152) Los principales reflejos de este principio son que los derechos fundamentales y sus respectivas normativas traen al legislador prohibiciones, deberes y limitaciones de su competencia.

En el mismo sentido, se tiene el principio de la progresividad que tiene su primera disposición a nivel internacional en la Declaración de los Derechos Humanos de 1948, y en la OIT. (MURADAS; 2011, p. 88) En el marco constitucional está presente cuando se observa la prevalencia de los derechos humanos (artículo $4^{\circ}$, II); de la recepción de derechos expresados en tratados y convenciones (artículo 5 , $\left.\S 2^{\circ}\right) ;$ y cuando se refiere a los derechos sociales de los trabajadores, estableciendo que no se trata de un rol taxativo (art. $7^{\circ}$ caput), ampliando la protección para otros derechos que que apunte a la mejora de su condición social. (MURADAS; 2011, p. 88) Además, como resaltado anteriormente los derechos humanos poseen papel esencial y componen los derechos fundamentales, a través

FRUSTAÇÃO E AO INADIMPLEMENTO, PELO PODER PÚBLICO, DE DIREITOS PRESTACIONAIS. - O princípio da proibição do retrocesso impede, em tema de direitos fundamentais de caráter social, que sejam desconstituídas as conquistas já alcançadas pelo cidadão ou pela formação social em que ele vive. - A cláusula que veda o retrocesso em matéria de direitos a prestações positivas do Estado (como o direito à educação, o direito à saúde ou o direito à segurança pública, v.g.) traduz, no processo de efetivação desses direitos fundamentais individuais ou coletivos, obstáculos a que os níveis de concretização de tais prerrogativas, uma vez atingidos, venham a ser ulteriormente reduzidos ou suprimidos pelo Estado. Doutrina. Em consequência desse princípio, o Estado, após haver reconhecido os direitos prestacionais, assume o dever não só de torná-los efetivos, mas, também, se obriga, sob pena de transgressão ao texto constitucional, a preservá-los, abstendo-se de frustrar - mediante supressão total ou parcial - os direitos sociais já concretizados. (BRASIL, Supremo Tribunal Federal, 2011). LA PROHIBICIÓN DEL RETROCESO SOCIAL COMO OBSTÁCULO CONSTITUCIONAL A LA FRUSTRACIÓN Y AL INADIMPLEMENTO, POR EL PODER PÚBLICO, DE DERECHOS PRESTACIONALES. - El principio de la prohibición del retroceso impide, en tema de derechos fundamentales de carácter social, que se desconstituyan las conquistas ya alcanzadas por el ciudadano o por la formación social en que él vive. - La cláusula que prohíbe el retroceso en materia de derechos a prestaciones positivas del Estado (como el derecho a la educación, el derecho a la salud o el derecho a la seguridad pública, $\mathrm{vg}$ ) traduce, en el proceso de efectividad de esos derechos fundamentales individuales o colectivos, obstáculos a que los niveles de concreción de tales prerrogativas, una vez alcanzados, sean posteriormente reducidos o suprimidos por el Estado. Doctrina. En consecuencia de este principio, el Estado, tras haber reconocido los derechos de prestaciones, asume el deber no sólo de hacerlos efectivos, sino que también se obliga, bajo pena de transgresión al texto constitucional, a preservarlos, absteniéndose de frustrar - mediante supresión total o parcial - los derechos sociales ya concretizados. (Traducción libre del autor) 
de la recepción de tratados internacionales. (MASSIMO; 2015, p.58) De esta forma, este principio representa la protección de los derechos sociales y así, cuando una ley trae una progresiva mejora y perfeccionamiento del derecho éste será incorporado como patrimonio jurídico de la ciudadanía y no puede ser absolutamente suprimido". (SARLET, 2004, p. 443)

Aún, cabe resaltar la posición de Adoración Guamán Hernández y Héctor Illueca Ballester (2012, p.54) en la perspectiva de la Constitución Española de 1978) que hay la existencia de un bloque de laboratividad, que tiene tres características: 1. la integración del conflicto capital-trabajo: se materializa por medio de tres instrumentos "el reconocimiento de los sindicatos libres y independientes [...], de la negociación colectiva [...] y de la autotutela colectiva [...]" (GUAMÁN HERNÁNDEZ; ILLUEGA BALLESTER; 2012, p.54) que se materializa en el derecho de huelga; 2. El reconocimiento de la negociación colectiva como fuente de derechos y obligaciones: reconociendo la institución política y la efectiva participación democrática (SCHWARZ; 2011, p. 76-77); 3. el carácter compensador o equilibrador de las normas que regulan las relaciones de trabajo, lo que efectivamente significa reconocer que hay sí desigualdades intrínsecas en las relaciones de trabajo, y por ello hay la necesidad de compensación del ordenamiento ligado al "compromiso constitucional por lograr no la igualdad formal pero la sustancial o real". (GUAMÁN HERNÁNDEZ; ILLUEGA BALLESTER; 2012, p.54)

En el ámbito brasileño, según Cleber Lúcio de Almeida y Wania Guimarães Rabêllo de Almeida (2017, p.127), es posible vislumbrar el bloque de laboratividad o laborista, una vez que la constitución: 1. Promueve la integración del conflicto capital-trabajo por medio de la libertad y autonomía sindical (art.8o), la propia negociación colectiva (artículo 7, XXVI y 8) y la autotutela por medio del derecho de huelga (artículo 9); 2. Reconoce la negociación como una fuente de derechos y obligaciones (artículo 7, XXVI); 3. Reconoce la existencia de la desigualdad intrínseca entre capital y trabajo y establece mecanismos de compensación, ya que reconoce los derechos fundamentales laborales (artículo 7 a 11), la explotación de cualquier actividad económica vinculada a la garantía de una vida digna (art. (170), el respeto a la normativa laboral como componente de la función social de la 
propiedad (artículo 186), todas estas perspectivas según el ideal de la construcción de una sociedad justa e igualitaria, vinculada a la erradicación de la pobreza y la marginación, desigualdades y promoción del bien de todos (art. 3oㅡ).

Por último, cabe resaltar la clasificación de Riccardo Guastani (2003, p.58) en la que hay siete condiciones de constitucionalidad, que son: existencia de una constitución rígida, garantía constitucional de la Constitución, fuerza vinculante de la Constitución, sobre interpretación de la Constitución, aplicación directa de la Constitución en las relaciones privadas, interpretación conforme a las leyes, e influencia de la Constitución sobre las relaciones.

Analizando la Constitución de 1988 se permite admitir que ella está de acuerdo con las siete condiciones de constitucionalidad (ALMEIDA; ALMEIDA, 2017, p.128) una vez que: es rígida, es escrita y está protegida por la legislación ordinaria; con una garantía jurisdiccional, ya que permite mecanismos de control (artículo 102, $\mathrm{I}, \mathrm{a})$; tiene fuerza vinculante; $y$ en el caso de que se trate de un proyecto de ley. es plenamente aplicable a las relaciones privadas (artículos 170 y 186); es un factor condicionante para la interpretación de las leyes; y ejerce influencia sobre las relaciones políticas, ya que está protegida contra el legislador ordinario y el poder constituyente derivado (artículo 60, § 4). Además, se resalta la extrema importancia del entendimiento de Riccardo Guastini (2003, p.54) cuando a un orden jurídico constitucionalizado: la legislación, la jurisprudencia, las relaciones privadas y el estilo doctrinal están condicionados por la Constitución. (ALMEIDA; ALMEIDA, 2017, p.128)

De esta forma, es posible concluir que la integración de la normativa laboral trabaja en tres niveles constitucional puro, derivaciones del bloque de constitucionalidad y del bloque de laboratividad. Se permite así, observadas las debidas compensaciones, la adaptación de la vivencia laboral a la realidad, sin que con ello se permita la usurpación de derechos históricamente conquistado.

Los derechos fundamentales irradian un límite de derechos a ser observados tanto por el Estado representado por el legislador, como por los ciudadanos, provocando un contrapeso entre la soberanía estatal y la soberanía popular ejercida en un Estado democrático de derecho. 
La Constitución del Trabajo de Brasil es una constitución fuerte e incluso realiza de forma efectiva la constitucionalización cualificada del derecho del trabajo, ya que impone el status fundamental al valor social del trabajo y calificó los límites del poder de empleo y del capital. (ALMEIDA; ALMEIDA, 2017, p.128)

\section{LA FUERZA DE LA CONSTITUCIÓN DE 1988 ANTE LOS RIESGOS DE LA REFORMA LABORAL DE 2017}

El Derecho del Trabajo es un derecho fundamental social y prescinde de forma permanente de esfuerzos en descubrir mecanismos y soluciones que lleven a la efectividad de las normas Constitucionales.

Conforme explica Dinaura Godinho Pimentel Gomes (2013, p.139) sólo así se hace posible obtener la efectividad de normas de protección de derechos sociales, en general, y de los derechos laborales, en particular, complementa además, que es necesario complementar la competencia económica con las exigencias de justicia social, tal como establece el Artículo 170 de la Ley Mayor (GOMES, 2013, p. 139), es decir, no basta con existir normativas constitucionales e internacionales (dentro de la perspectiva de bloque de constitucionalidad), éstas necesitan ser aplicadas inmediatamente y la legislación infraconstitucional no puede restringir, suprimir el limitar tales derechos.

Cabe la duda de cómo se da esa eficacia jurídica, la aplicabilidad inmediata, y tal hecho es aclarado por Ingo Wolfgang Sarlet (2003, p.222) cuando afirma que consiste justamente en la posibilidad de aplicación de la norma a los casos concretos, con la consiguiente generación de los efectos jurídicos que le son inherentes.

Aclarece además que la eficacia jurídica se define como la posibilidad (en el sentido de aptitud) de que la norma vigente (jurídicamente existente) se aplica a los casos concretos y - en la medida de su aplicabilidad - generar efectos jurídicos (SARLET, 2003, p.222). Ahora, si la comprensión es en relación a la eficacia social (o efectividad) puede ser considerada como englobando tanto la decisión por la 
efectiva aplicación de la norma (jurídicamente eficaz), cuanto el resultado concreto resultante - o no - de esta aplicación. (SARLET, 2003, p.223)

En el presente estudio, la efectividad está ligada a la noción de eficacia social de la norma que, en la definición de Luís Roberto Barroso (1996, p.83), significa la realización del Derecho, el desempeño concreto de su función social. Que representa la materialización, en el mundo de los hechos, de los preceptos legales, y simboliza la aproximación, tan íntima como sea posible, entre el deber de ser normativo y el ser de la realidad social.

Como observar entonces si todo el marco presentado sobre la fuerza de la Constitución, de los principios, del bloque de constitucionalidad de una forma general y del bloque de laboratividad efectivamente tiene fuerza de barrer reformas que busquen suprimir y revocar derechos fundamentales del trabajo.

La crítica neoliberal al Derecho del trabajo lo transforma en enemigo del derecho al trabajo (ALMEIDA; ALMEIDA, 2017, p.120), bajo el argumento de que las normativas que componen el derecho del trabajo actúan como obstáculo a las contrataciones y así al derecho al trabajo. Tal afirmación no encuentra respaldo, ya que no se ha comprobado que la disolución de normas protectivas aumenta el número de personas empleadas.

La efectividad de los derechos fundamentales al trabajo se vuelve más compleja, ya que las relaciones de trabajo, son fuertemente marcadas por el histórico desequilibrio de fuerzas que hizo surgir el Derecho del Trabajo, aún contemplando lo hiposuficiente en esa relación que necesita contar con el apoyo del Estado (AZEVEDO; OSÓRIO, 2008, p.16).

La intervención legislativa se observa en dos niveles, primero en el propio texto constitucional por medio de Enmiendas Constitucionales, de las 99 (noventa y nueve) publicadas hasta diciembre de 2017, cuatro involucra cuestiones de naturaleza material y procesal dirigidas a las relaciones de trabajo: 1. Enmienda Constitucional no. 28, de 25.05.2000, modificó la redacción del inciso XXIX del art. 7, sobre el derecho de acción, cuanto a los créditos resultantes de las relaciones de trabajo, con plazo prescripcional de cinco años para los trabajadores urbanos y rurales, hasta el límite de dos años después de la extinción del contrato de trabajo; 
2. Enmienda Constitucional №. 45, de 30.12.2004, modificó la redacción de diversos artículos de la Carta Constitucional y, en particular, el artículo 114 ampliando la competencia material y procesal de la Justicia del Trabajo; 3. Enmienda Constitucional o․ 53 de 19.12.2006, modificó el inciso XXV del artículo 7, relativo a la asistencia gratuita a los hijos y dependientes desde el nacimiento hasta 5 (cinco) años de edad en guarderías y preescolares; y 4. Enmienda Constitucional ํo. 72, de 02.04.2013, modificó el párrafo único del artículo 7, estableciendo la igualdad de derechos laborales entre los trabajadores domésticos y los demás trabajadores urbanos y rurales.

Según Azevedo y Osório (2008, p.16) el Estado debe eximirse al máximo su intervención legalista en el Contrato de Trabajo, sin embargo, debe ejercer con más intensidad su atribución esencial, sea cual, la garantía de la efectividad de lo que está regulado, en la ley o en el contrato, a fin de que haya seguridad jurídica y paz entre la comunidad.

Además de las disposiciones en pie de constitucional, recientemente una legislación infraconstitucional vino con la fuerza de amenazar toda la estructura protectora anteriormente mencionada: La reforma Laboral.

El 11 de noviembre de 2017 entró en vigor la Ley №. 13.467 / 2017 denominada de Reforma Laboral, trayendo nuevos conceptos para las relaciones de trabajo y valorizando la negociación sindical, intentando de cierta forma retirar del Estado su participación intervencionista en materia laboral.

De las alteraciones aprobadas destacan: alteraciones en la caracterización del grupo económico; de la sucesión de empleadores y responsabilidad de socio retirado; del vínculo de empleo, trabajo autónomo, trabajo por régimen parcial e intermitente; del teletrabajo; de la jornada de trabajo y tiempo a disposición; del intervalo; de las vacaciones; del daño fuera del balance; del trabajo de la mujer; del poder directivo del empleador; de las remuneraciones e integraciones; de las equiparaciones e isonomía salarial; de la rescisión contractual; de la aprobación de la gestión de la rescisión contractual, PDV y la aprobación de la gestión anual; de la posibilidad de arbitraje; del derecho procesal del trabajo; de la prescripción; en la propia ley de tercerización; y en el derecho colectivo del trabajo, en los puntos de 
representación de empleados en la empresa, impuesto sindical y contribuciones sindicales y de la determinación de la fuerza del negociado sobre legislado.

La amplia mayoría de los cambios no tienen compatibilidad con el sistema de bloque de constitucionalidad ${ }^{5}$ que, como se mencionó anteriormente, puede ser entendido como el conjunto de normas que junto con la constitución de un Estado, forman un bloque normativo de nivel constitucional (LOPES; MORAES, 2008, p.25), en igualdad de importancia y jerarquía.

Los términos de la referida legislación fueron objeto de la $2^{\text {a }}$ Jornada de Derecho Material y Procesal del Trabajo, en el que se aprobaron 125 enunciados, dirigidos a la interpretación de la denominada "Reforma Laboral", y que se justifican según Guilherme Guimarães Feliciano (2008), Presidente de la ANAMATRA en razón de que dicha ley fue aprobada con diversos vicios y carece de una interpretación de los magistrados a la luz de la Constitución y de los convenios y tratados.

Ante este posicionamiento, hay que recordar la interpretación dada por Carlos Sánchez Viamonte (1956, p.1), para la distinción entre derechos y garantías, pues por el pensamiento del autor, no basta la existencia del derecho, debe ocurrir la garantía, la institución creada a favor del individuo, para que, armado con ella, pueda tener a su alcance inmediato el medio de hacer efectivo cualquiera de los derechos individuales que constituyen en conjunto la libertad civil y política.

Se demuestra inadmisible que la eficacia de los derechos sociales y su desarrollo estén exclusivamente restringidos al legislador, ya que tales derechos poseen todo el marco constitucional y así, no son sólo una recomendación y sí, establecen el deber jurídico de legislar. (NETO BITENCOURT, 2010, p.159)

A pesar de ello, como se resalta anteriormente, los diversos intentos de supresión y reducción de los derechos fundamentales sociales del trabajo son reflejos de la tendencia y discursos de flexibilización. Este embate está

\footnotetext{
${ }^{5}$ A expressão "bloc de constitucionalité" originou-se na doutrina administrativista francesa, iniciada por Maurice Hauriou, a partir da criação de um "bloco de legalidade" das atividades desempenhadas pelo Conselho do Estado (que exercia o controle dos atos administrativos na França). A existência de um conjunto de normas, em um sistema jurídico, composto por um todo normativo de igual hierarquia, foi posteriormente incorporada ao direito constitucional. (FAVOREU; RUBIO LLORENTE, 1991, p. 20)
} 
concretamente dividido entre dos corrientes: una (en su mayoría representada por sectores de las clases empresarias) defiende la flexibilización en grado máximo, alcanzando hasta la total desregulación (RAMOS FILHO, 2012, p.49); y otra (defendida por sectores normalmente vinculados a la defensa de los derechos de los trabajadores) buscan incluso incentivar una mayor reglamentación. (PINTO, 2012, p.85)

Los ideales de desregulación surgen como una fuerte crítica a la interferencia estatal y el exceso de leyes trabajaría contra la lógica del mercado de trabajo. (RAMOS FILHO, 2012, p.49) Por otro lado, en el siglo XXI la desregulación se daría por una actuación estatal en favor de la clase empresarial. (RAMOS FILHO, 2012, p.49)

Lo que se verifica, consolidado por las mayorías de los cambios presentados por la reforma laboral, es un verdadero mercado de los productos legislativos que significa la utilización del ordenamiento jurídico laboral con el objetivo de satisfacer las voluntades y necesidades del mercado financiero. (AMADO; 2009, p. 163) Este fenómeno es intitulado por algunos autores como "darwinismo normativo": el derecho es visto como un producto en competencia y de esa forma, se optar por las normas jurídicas más adecuadas a las necesidades y prioridades del orden económico y de forma paralela, si los ordenamientos jurídicos que más favorecen la eficiencia de la economía, creando así un "mercado de las legislaciones". (SUPIOT, 2005, p.132) Estas adaptaciones y elecciones son intituladas por Antonio Monteiro Fernandes como la "instrumentalidad económica de la ley laboral". (FERNANDES, 2014, p.23)

Estas circunstancias de negociación de los derechos y la adaptación de ellos permiten cada vez más alejarse de las bases, estructuras y conquistas del derecho laboral, ampliando espacio para la precarización del trabajo, tercerización y desregulación de normas laborales, etc. Hay entonces, una inversión de la lógica laboral para la menor protección del trabajador. (PADILHA, 2017, p.127)

Se amplía entonces, según Antonio Casimiro Ferreira, el camino hacia un "derecho del trabajo de excepción" y así, siguen los patrones capitalistas actuales y forman parte de un sistema de "austerización" (FERREIRA, 2013, p.130-131) Este 
sistema se construye a través del análisis del costo-beneficio del empleo y es donde se pone en riesgo el carácter protector del derecho del trabajo. (PADILHA, 2017, p.127)

La realidad de las sucesivas reformas que Brasil enfrentó, como la propia tercerización, ${ }^{6}$ los derechos mínimamente regulados, como de los empleados domésticos regulados solamente con la enmienda constitucional no 72/2013, y la Ley № 13.467 / 2017, demuestran que los discursos de flexibilización y desregulación, cuando se materializan y se colocan ante la realidad de crisis económicas y desempleo, generan solamente el subempleo y la precarización del derecho al trabajo. (ZOCKUN, 2010, p.208-209)

Las transformaciones y adaptaciones del derecho del trabajo a las realidades económicas y sociales son inevitables, sin embargo, no es adecuado la aceptación de una inversión completa en la esencia proteccionista del derecho laboral. (PADILHA, 2017, p.128)

Para ello, se demostró el principio de la prohibición del retroceso social, entendido como un principio básico para la concreción de los derechos fundamentales. Ana Paula de Barcellos y Roberto Barroso afirman que el principio del retroceso social es aplicable a la legislación infraconstitucional de todos los derechos constitucionales. Por otro lado, Felipe Derbli defiende que esta aplicación sería sólo a los derechos fundamentales sociales. (SCHIER, 2009, p.152)

Independientemente de la posición defendía, hay una doctrina consolidada que garantiza la protección del principio de la prohibición del retroceso social a las normativas constitucionales e incluso a la legislación infraconstitucional, como la propia CLT, una vez que ésta es consecuencia de derechos fundamentales sociales expresados en la constitución. Los cambios que busquen suprimir o desestabilizar el instituto deben ser hechos de forma justificada y compensada, como se elabora anteriormente, sin embargo tal hecho no ocurrió en la reforma laboral.

El principio del vedamiento del retroceso es esencial para la protección de los derechos de los trabajadores, por ser uno de los principales elementos que

${ }^{6}$ Sobre la temática consultar: ANTUNES; DRUCK, 2013 e FIGUEIREDO; HAZAN, 2014. 
garantiza la efectividad de derechos construidos y garantizados en el ordenamiento, y también, ya con la posición de principio garantista de la progresividad de los derechos fundamentales, actúa impidiendo alteraciones negativas y supresoras. (MURADAS, 2001, p.85)

De esta forma, se defiende en este estudio la aplicación del principio del vedamiento del retroceso social cuando éste y sus justificaciones estén amparadas en la supremacía de la Constitución Federal y sus principios, y que objetiven la máxima eficacia de los derechos fundamentales. Se queda entonces, el legislador imposibilitado de retroceder de forma desproporcionada (DERBLI, 2007, p.34) sólo siendo permitido que haya ese retroceso cuando se demuestra la pertinencia, necesidad y la ponderación como justificación. (NETTO E PINTO, 2010, p.202)

Además, lo que se observa es que si por un lado el grado de constitucionalización formal del derecho del trabajo es elevado, por otro lado en cuanto al grado de constitucionalización sustancial la constitución del trabajo es débil. Ante las sucesivas reformas realizadas en la legislación laboral se observa que en diversos momentos los límites y protecciones constitucionales, de tratados, convenciones y principios no son observados. Diversas legislaciones establecen jornadas exorbitantes, alcanzando doce horas; varias decisiones niegan la fuerza normativa de la constitución cuando se niega la aplicabilidad de los convenios; no se aplica como regla el análisis y crítica de la normativa laboral a la luz de la constitución y aún, persiste la falta de respeto e inobservancia, por los empleadores, a los derechos constitucionalmente previstos como la propia duración de la jornada, descansos y etc. (ALMEIDA; ALMEIDA, 2017, p.129)

Además, todavía quedan alternativas ante la omisión legislativa en cuanto a los patamentos constitucionales: el control de constitucionalidad y convencionalidad. Brasil combina el criterio difuso, por vía de defensa, con el criterio concentrado, por vía de acción directa de inconstitucionalidad, y ahora, consolidando una incorporación de la acción de inconstitucionalidad por omisión (arts. 102, I, a e III, e 103). (SILVA, 2003, p.554)

La Constitución de 1988 creó procedimientos de control contra las omisiones normativas inconstitucionales en sede concreta se cita el mandamiento de 
requerimiento, art. 5으, LXXI, CRFB); como de forma abstracta: la acción directa de inconstitucionalidad por omisión, art. 103, § 2oㅡ, CRFB); y, además, posibilita la acusación de incumplimiento de precepto fundamental en el art. 102, §1ํㅡ, CRFB.

Otra innovación camina como mecanismo de defensa de la Constitución: es la ampliación del rol de legitimados para la proposición de la acción directa de inconstitucionalidad. Se permite hoy a los Estados la institución de acción directa para la declaración de inconstitucionalidad de algún acto normativo estadual o municipal frente a la Constitución Estatal (art. 125, §2oㅡ, CF).

Entre otras innovaciones, la Constitución de 1988, consagró el complejo sistema de constitucionalidad brasileño, que combina influencias externas diferentes, y así, admite tanto el control difuso como el incidental, de forma represiva, y, en ciertos parámetros, el control previo.

De esta forma, sólo se demuestra posible y plausible la constitucionalidad de la reforma de los derechos sociales laborales, y así, su recepción al ordenamiento, si se ponen medidas compensatorias y estudios en profundidad sobre los impactos de tales retrocesos. Es inadmisible la reducción arbitraria del nivel de concreción legislativa de dicha categoría de derechos fundamentales. (DERBLI, 2008, p.334) En caso contrario, es evidente la imposición del principio de la prohibición del retroceso y el incumplimiento de la fuerza progresiva de los derechos fundamentales sociales $y$, por consiguiente, su inconstitucionalidad.

Por tanto, abogaba por que una vez obtenidas garantías y mejoras para los derechos sociales, en virtud de la prohibición del retroceso, y con base en la dignidad de la persona humana, en el principio de la confianza, la seguridad de los ciudadanos (CANOTILHO, 2003, p.338-339), y todas las protecciones derivadas de tratados y convenciones internacionales, éstas deben prevalecer en detrimento de alteraciones legislativas injustificadas e infundadas. Si no se realiza el filtrado de forma previa por el legislativo y ejecutivo, existe la posibilidad, garantizada constitucionalmente, de la realización del control de constitucionalidad y convencionalidad de forma amplia por todos los ciudadanos, a través de mecanismos difusos y por los legitimados, por medio de mecanismos directos. La defensa de los derechos fundamentales al trabajo es una obligación de todos. 
Se resalta, por lo tanto, que el objetivo de esta aplicación es impedir la frustración de la efectividad constitucional (SARLET, 2004, p.456), estimular el perfeccionamiento del sistema de protección de los derechos fundamentales $\mathrm{y}$, principalmente, la protección de las conquistas históricamente alcanzadas. El resultado es el alcance más cercano a la dignidad efectiva de las relaciones de trabajo.

\section{CONCLUSION}

La Constitución brasileña de 1988, en sus más de 30 años de existencia, cumple su papel de instrumento guía para la nación, pero tal realización encuentra diversas barreras y dificultades reflexivas en el extenso rol de enmiendas, en el fortalecimiento de teorías que busca transformar la carta en apenas "intenciones", o aún, legislaciones infraconstitucionales que afrontan de la normativa constitucional, pero permanecen y rigen en el ordenamiento.

Los riesgos son grandes, pero la fuerza de los derechos fundamentales viene tomando proporciones protectivas y formando un bloque de constitucionalidad, incluyendo así el texto de la carta, pero también principios, tratados y convenciones, forman una barrera que todos, dentro del Estado democrático de derecho, deben defender.

La frustación es latente, frente a diversas normativas infraconstitucionales que corrompen, desestructuran y que efectivamente nunca pasaron por el filtro del bloque de constitucionalidad, el filtro, que debería ser previo, muchas veces es barganado por intereses que no concatan con los ideales democráticos y de formación de una sociedad justa e igualitaria.

En el texto magno, todavía queda la esperanza, ya prevista en el texto magno, el control de constitucionalidad y convencionalidad a ser realizado por todos, como defensores del texto que los defiende. Este control debe realizarse incesantemente, no hay tiempo o situación que justifique que una normativa desestructure todo un sistema de protección, garantías y construcción de una 
sociedad efectiva, solidaria y progresiva en materia de derechos fundamentales, aquí en especial al derecho propulsor de diversas oportunidades: el derecho al trabajo y el derecho del trabajo.

\section{REFERENCIAS}

ALEXY, Robert. Teoría de los derechos fundamentales. 2. ed. Madrid: Centro de Estudios Políticos y Constitucionales, 2007.

ALMEIDA, Cleber Lúcio de; ALMEIDA, Wânia Guimarães Rabêllo de. Direito do Trabalho e Constituição: A constitucionalização do direito do trabalho no Brasil. São Paulo: LTr, 2017.

AMADO, João Leal. Dinâmica das relações de trabalho nas situações de crise. In: Revista do Ministério Público, ano 30, № 120, p.187-100, 2009.

ANTUNES, Ricardo; DRUCK, Graça. A terceirização como Regra. In: Revista TST. Brasília, vol. 79, № 4, out/dez. 2013

AZEVEDO, André Jobim de; OSÓRIO, Guilherme Luiz Thofehrn. Direito do Trabalho, Constituição e Efetividade. In: Direito Constitucional do Trabalho Vinte Anos Depois Constituição Federal de 1988 - Constituição Federal de 1988. VILLATORE, Marco Antônio César; HASSON, Roland (coord.); ALMEIDA, Ronald Silka de (org.). Curitiba: Juruá, 2008.

BARBOZA, Estefânia Maria de Queiroz. Jurisdição Constitucional: entre constitucionalismo e democracia. Belo Horizonte: Fórum, 2007.

BARROSO, Luís Roberto. O Direito Constitucional, e a efetividade de suas normas. 3. ed. Rio de Janeiro: Renovar, 1996.

BENEVIDES, Maria Victoria de Mesquita. A cidadania ativa - referendo, plebiscito e iniciativa popular. São Paulo: Ática, 1991.

BRASIL, Supremo Tribunal Federal. Agravo em Recurso Extraordinário no 639337. Relator(a): Min. CELSO DE MELLO, Segunda Turma, julgado em 23/08/2011.

CANOTILHO, J.J. Gomes. Direito constitucional e teoria da constituição. 7. ed., 11 reimp. 
CLÈVE, Clémerson Merlin. A eficácia dos direitos fundamentais sociais. In: Revista de direito constitucional e internacional. São Paulo: RT. v. 14. №. 54, pp. 28-39, jan./mar. 2006.

DELGADO, Mauricio Godinho. Curso de Direito do Trabalho. 14. ed. São Paulo: LTr, 2015.

DERBLI, Felipe. A aplicabilidade do princípio da proibição de retrocesso social no direito brasileiro. In: SOUZA NETO, Cláudio Pereira de; SARMENTO, Daniel (Orgs). Direitos Sociais, fundamentos, judicialização e direitos sociais em espécie. Rio de Janeiro: Lumen Juris. 2008.

DUTRA, Silva Regina Bandeira; VILLATORE, Marco Antônio César. Teletrabalho e direito à desconexão. In: Revista do Tribunal Regional do Trabalho da 9a Região. V. 3, ำ 33. set./2014.

FAVOREU, Louis; RUBIO LLORENTE, Francisco. El bloque de la constitucionalidad: simposium franco-espanhol de derecho constitucional. Madri: Civitas, 1991.

FELICIANO, Guilherme Guimarães. Jornal ANAMATRA - Associação Nacional dos Magistrados da Justiça do Trabalho Ano XXI, ํo. 189, 2017. Disponible en: https://www.anamatra.org.br/attachments Jornal_Anamatra_189_26-12-17.pdf. Acesso em 11 jan. 2018.

FERNANDES, Antônio Monteiro. Direito do Trabalho, 17. ed. Coimbra: Coimbra Editora, 2014, p.23.

FERREIRA, Antônio Casimiro. Exercício de funções públicas em tempo de crise. In: Trabalho em funções públicas em termos de crise: que direito(s)?: atas da I Jornadas de Direito do Emprego Público. Porto: Sindicato dos Trabalhadores em Funções Públicas e sociais do norte, 2013.

FIGUEIREDO, Bruno Reis de; HAZAN, Ellen Mara Ferraz. (Org.). Alguns aspectos sobre a terceirização. Belo Horizonte: RTM, 2014, v. p. 265-278.

GIUBONNI, Stefano. II primo dei diritti sociales. Riflessioni sul diritto al lavoro tra Costituzione italiana e ordenamento europeu. 2006. Disponible en: $<$ http://aei.pitt.edu/13686/1/giubboni_n46-2006int.pdf>.

GOMES, Dinaura Godinho Pimentel. Exigência de Efetividade dos Direitos Assegurados pela Consolidação das Leis do Trabalho, através de Medidas Judiciais de Tutela Coletiva. In: CLT 70 anos de consolidação: uma reflexão social, econômica e jurídica. CAVALCANTE, Jouberto de Quadros Pessoa; VILLATORE, Marco Antônio César. São Paulo: Atlas, 2013. 
GUAMÁN HERNÁNDEZ, Adoración; ILLUEGA BALLESTER, Héctor. El huracán neoliberal: una reforma laboral contra el trabajo. Madrid: Ediciones Sequitur, 2012.

GUASTINI, Ricardo. La constitucionalización del ordenamiento jurídico: el caso italiano. In: CARBONELL, Miguel (Org.). Neoconstitucionalismo(s). Madrid: Editorial Trotta, 2003.

HABERMAS, Jürgen. Directo e democracia: entre facticidade e validade. v. I. 2. ed. tradução: Flavio Beno Siebeneichle. Rio de Janeiro: Tempo Brasileiro, 2010.

HACHEM, Daniel Wunder. Tutela administrativa efetiva dos direitos fundamentais sociais: por uma implementação espontânea, integral e igualitária. Curitiba, 2014. 614 f. Tese (Doutorado em Direito) - Programa de Pós-Graduação em Direito, Universidade Federal do Paraná. 2013.

HERRERA, Miguel Argel García. Estado social y estado económico. Jueces para la democracia, $\mathrm{n}^{\circ}$ 84, 2015.

LOPES, Ana Maria D’Ávila. Bloco de constitucionalidade e princípios constitucionais: desafios do poder judiciário. In: Revista Sequência, oㅡ 59, p. 43-60, dez. 2009.

; MARQUES, Samuel de Araújo. O bloco de constitucionalidade o direito comparado e no direito brasileiro. In: RODRIGUES, Francisco Luciano Lima. Estudos de direito constitucional e urbanístico. São Paulo, RCS, 2007.

; MORAES, Ismael Evangelista Benevides. Direito constitucional. 2 ed. Fortaleza: LCR, 2008b.

MAGANO, Octávio Bueno. Revisão constitucional. In: Cadernos de Direito Constitucional e Ciência Política, № 7, São Paulo, p. 108-112, abr./jun. 1994.

MASSIMINO, Leonardo F. La Intervencion estatal, la regulacion econômica y el poder de policia: analy e tendências. In: Revista Direito Econômico e Socioambiental. Curitiba, v. 6, n. 1, p. 36-63, jan/jun 2015.

MIKOS, Natália Regina de Carvalho. Trabalho doméstico no brasil: os reflexos trabalhistas e previdenciários da nova regulamentação. In: Monografia apresentada para a conclusão do curso de direito da Universidade Federal do Paraná. 2015.

MURADAS, Daniela. O Princípio da Vedação do Retrocesso Social no Direito Coletivo do Trabalho. In: Revista Síntese Trabalhista. n. 262. Abril 2011.

NETO BITENCOURT, Eurico. O Direito ao mínimo para uma existência digna. Porto Alegre: Livraria do Advogado. 2010. 
NETTO E PINTO, Luísa Cristina. O Princípio de Proibição do Retrocesso Social. Porto Alegre: Livraria do Advogado, 2010.

PADILHA, Viviane Herbst. Direito do trabalho na crise ou a crise do direito do trabalho? In: Direito material e processual do trabalho. Maria Cecília Máximo Teodoro...[et al], coordenadores. São Paulo: LTr, 2017.

PÉREZ LUÑO, Antonio Enrique. Los derechos fundamentales. 6. ed. Madrid: Tecnos, 1995.

PINTO, Flavia Aguiar Cabral Furtado. Os Direitos Fundamentais Sociais dos Trabalhadores como Limites ao Princípio da autonomia da vontade e a Flexibilização das Relações de Trabalho no Estado Democrático de Direito. Fortaleza, 2012. 106 f. Dissertação (Mestrado em Direito) - Programa de PósGraduação em Direito, Universidade de Fortaleza (UNIFOR).

MARTÍNEZ DE PISÓN, José. Derechos Humanos: historia, fundamento y realidad. Zaragoza: Editorial Cometa, 1997.

RAMOS FILHO, Wilson. Direito Capitalista do Trabalho: História, Mitos e Perspectivas no Brasil. São Paulo: LTr, 2012.

REALE, Miguel. O direito de não trabalhar. In: Tendências do Direito do Trabalho Contemporâneo. Cássio Mesquita Barros Jr. (Coord.) São Paulo: LTr, 1980, V.I.

REISSINGER, Simone. Reflexões sobre a efetividade dos direitos fundamentais sociais. In: XVI Congresso Nacional do CONPEDI, 2007, Belo Horizonte.

SÁNCHEZ VIAMONTE, Carlos. El Habeas Corpus: La liberdade y sua garantia. Buenos Aires: Perrot, 1956.

SARLET, Ingo W.; FIGUEIREDO, Mariana. Reserva do possível, mínimo existencial e direito à saúde: algumas aproximações. In: SARLET; TIMM (Org.). Direitos fundamentais: orçamento e "reserva do possível". Porto Alegre: Livraria do Advogado, 2008.

SARLET, Ingo Wolfgang. A eficácia dos Direitos Fundamentais. 3‥ ed. rev. atual e ampl. Porto Alegre: Livraria do Advogado, 2003.

SCHIER, Adriana da Costa Ricardo. Regime Jurídico do Serviço Público: Garantia Fundamental do Cidadão e Proibição do Retrocesso Social. Curitiba, 2009. Tese (Doutorado em Direito) - Programa de Pós-Graduação em Direito, Universidade Federal do Paraná.

SCHMITT, Carl. Verfassungsrehctliche Aufsätze. 2a . ed. Berlin: Dumcker \& Humblot, 1973. p. 190. 
SCHWARZ, Rodrigo García. Los derechos sociales como derechos humanos fundamentales: su imprescindibilidade y sus garantías. México: Miguel Ángel Porrúa, 2011.

SEN, Amartya. Desenvolvimento como liberdade. Tradução de Laura Teixeira Motta. São Paulo: Companhia das letras, 2000.

SILVA, José Afonso da Silva. Curso de direito constitucional positivo. São Paulo: Malheiros, 2003.

SUPIOT, Alain. O direito do trabalho ao desbarato no "mercado das normas". Questões Laborais, ano XII, № 26, 2005.

VIANA, Márcio Túlio. O longo meio século do direito do trabalho no Brasil. In: Cinquenta años de Derecho del Trabajo em América Latina. Arturo Bronstein (Coord.). Santa-fé: Rubinzal-Culsoni, 2007.

VILLALOBOS, Maria Patrícia Kurczyn. Razón de ser del derecho del trabajo. In: Boletim Mexicano de Direito Comparado. Nueva serie, no 82, enero-abril XXCIII, Instituto de Insvestigaciones Jurídicas, UNAM, México, 1995, p.169-203. Disponible en: <www.juridicas.unam.mx;publica/rev/boletim/cont/82/art/art7.hmt>.

WANDELLI, Leonardo Vieira. A reconstrução normativa do direito fundamental ao trabalho. In: Revista TST, Brasília, vol. 79, № 4, out/dez 2013.

ZAGREBELSKY, Gustavo. Fundata sul lavoro: la solitudine dell'articulo 1. Torino: Giulio, 2013.

ZOCKUN, Carolina Zacaner. A Intervenção do Estado na Ordem Social e o Direito ao Trabalho. In: SPARAPANI, Priscila; ADRI, Renata Porto (Coord.). Intervenção do Estado no domínio econômico e no domínio social: homenagem ao Professor Celso Antônio Bandeira de Mello. Belo Horizonte: Fórum, 2010. 